\title{
Garden Cities: Lessons from Germany
}

\author{
KARL ECKERT
}

Karl Eckert is a senior at the BCRP program, City and Regional Planning Department, Cal Poly.

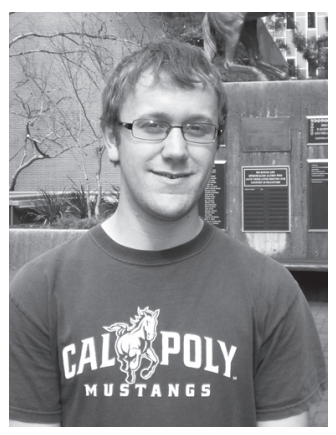

Figure 1 The Siemens factory, which was the main employment outlet for those living in Seimensstadt.

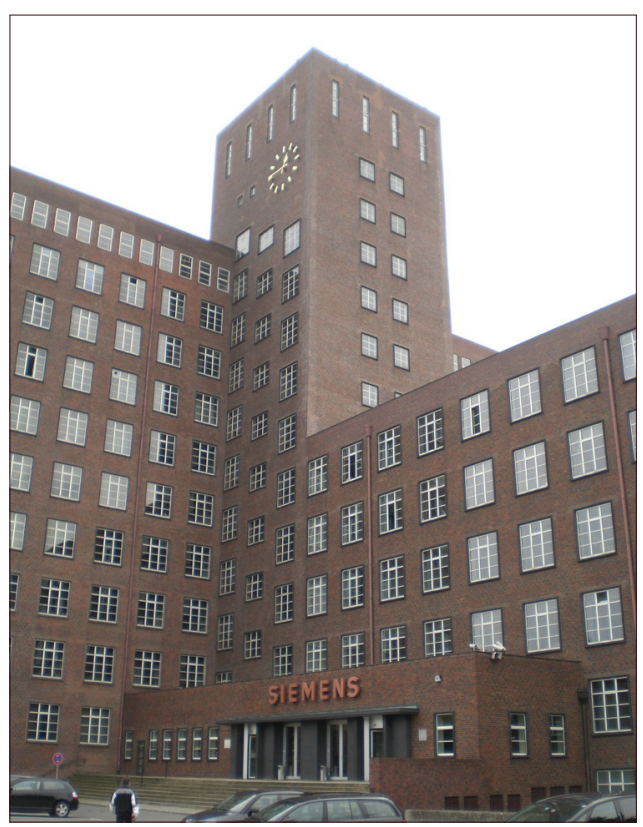

\section{Life in the Slums}

Ebenezer Howard's lessons and the Garden City movement spread throughout Europe between the end of the 19th century and the beginning of the 20th. In this article, Karl Eckert discusses the origins of the movement and the translation of the concept to Germany. During a recent trip, he visited and studied tSiemensstadt and Britz, two garden cities located in what now are the suburbs of Berlin.

In reading the book Cities of Tomorrow by Sir Peter Hall, one comes to realize the profession of planning is a relatively new field of expertise. Modern day city planning stems from the early 1900's when the societies of the developing world were dealing with the menace of the urban slum, a new phenomenon spurred by industrial forces and a rise in migratory populations to major city centers for employment. Developing ideas that would counter-attack this dire urban condition would soon define and establish what is known today as city planning.

Peter Hall's Cities of Tomorrow elaborates on how, during the period of 1880 to 1920 , major cities such as London, Berlin, Paris and New York experienced complications with slum populations. These cities exhibited high concentrations of poor residents within areas defined by the lack of physical maintenance, crowded conditions, disregard for sanitation, and general social decline. Andrew Mearns, a pamphlet writer of the time, described the slums of London with clarity:

"Few who read these pages have any conception of what these pestilential human rookeries are, where tens of thousands are crowded together amidst horrors which call to mind what we have heard of the middle passage of the slave ship. To get to them you have to penetrate courts reeking with poisonous and malodorous gases arising from accumulations of sewage and refuse scattered in all directions and often flowing beneath your feet; courts, many of them which the sun never penetrates, which are never visited by a breath of fresh air, and which rarely knows the virtues of a drop of cleansing water. You have to ascend rotten staircases, which threaten to give way beneath every step, and which, in some cases, have already broken down, leaving gaps that imperil the limbs and lives of the unwary." (Hall, 2002).

When large amounts of people lived in such areas, crime and socially destructive practices would take place. The slums became known as the "vice" areas for the city and were generally feared for the crime within.

The slum issue persisted because the people who lived in such areas were generally poor and lacked the ability to move into neighborhoods of better condition. Instead they were forced to live in these dire urban conditions to be close to what casual jobs they could find and hold. Living in the country away from the mess of the city offered no means of making money, since rural areas were void of the economic activity cities exhibited. 
The first attempts at ridding society of the menace the slum environment imposed included the actual physical tearing down of the cramped and unsanitary housing complexes in London. After the demolition, construction would begin building newer developments to rid the area of its previous record. Unfortunately, the new developments were seen as failures because the rent for the housing was out of reach for the people who previously lived in the area. So the now displaced inhabitants had to look for housing similar to their previous situation because they could not afford much else. This, of course, perpetuated the slum within the city, and where as the new developments did a general service to the area made anew, the slum would move and manifest itself somewhere else. The failure of the redevelopment programs, quite simply, is attributed to how the new developments did not address the social and economic demographics of the population in the slums. Eventually, after seeing no

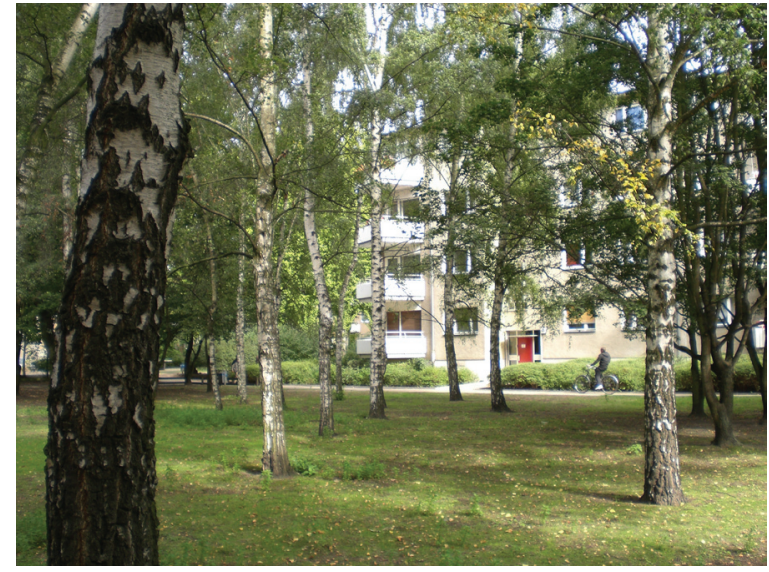

Figure 2

One type of open space found in Siemennstadt, to which all the building units open up towards.

\section{The Garden City Concept}

To address the dire conditions of the slum era, a line of thought developed to address the problems of the layman worker in the slum environment and, in turn, created the planning profession as we know it today. Hall recognizes that the main proponent of this line of thought was Ebenezer Howard (1850-1928) working in London and describes his idea in great detail. Howard, through adapting the thoughts of many other thinkers of his time, (a list so extensive as to be sufficient for a separate paper) developed and made popular the notion of creating what he dubbed "The Garden City". Inspiration for the concept came from many angles, for example, the key concept of a planned city (an idea somewhat foreign to Howard, being initially a shorthand writer) such as low population density, good housing, wide roads, open space and underground railway was first offered to Howard from a pamphlet titled Hygenia, or the City of Health by Benjamin Ward Richardson. Also at the time, there was a wide spread agricultural depression in Britain, causing rural land prices to plummet. To take advantage of the situation, Tomas Spence came up with the idea of purchasing the land on which a city was to be built, so construction on the land would cause the future land prices to rise. The profit from the higher land prices would be directed to the inhabitants of the city when parcels were exchanged between private interests. These are but a few of the ideas incorporated into the final garden city concept by Howard.

Howard also saw the problem of competing advantages and disadvantages between city environments and small rural towns. The garden city was to become a fusion of the two, taking the advantages each had to offer and disregarding the disadvantages. The Three Magnets figure by Howard shows the concept. The diagram places the values, both positive and negative, of the two competing atmospheres and provides the solution through the hybrid of the two, called the Town Country (the academic term of the physical garden city). Where as the city lacked interaction with nature and exhibited extensive and stressful working conditions, the country lacked the amusement and employment of cities demanded by most residents. The Town Country

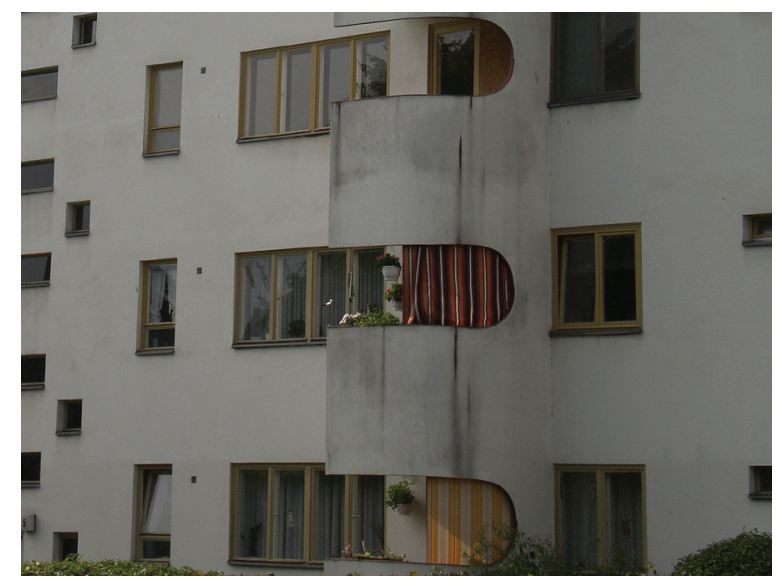

Figure 3

Different architectural elements on separate buildings help the residents of Siemensstadt identify with where they live. 


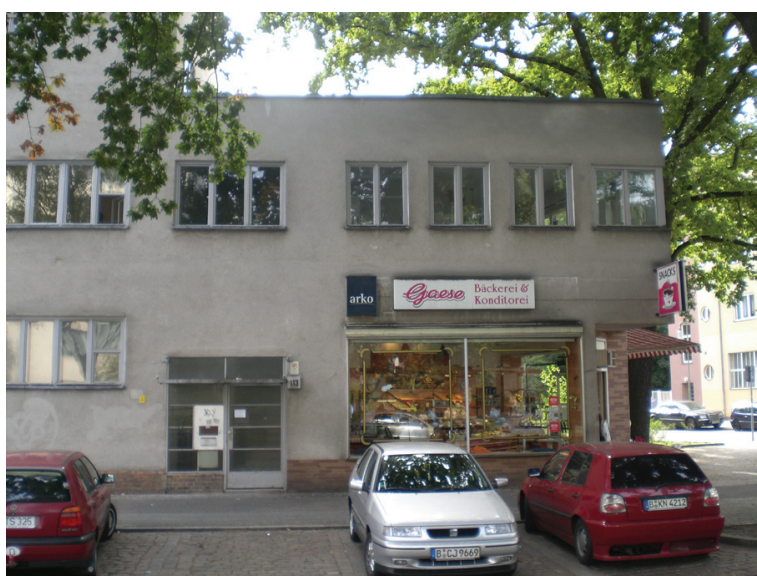

Figure 4

Corner shops are also an important feature in Seimensstadt, providing the residents with needed supplies, such as this bakery. was to address the various demands and considerations of the resident within a comprehensive environment, altering the social fabric of the people living within the planned community.

Finally, the garden city idea under Howard's vision included creating areas of community building and cooperation. In his mind this is achieved through the collective management of the resources in each garden city. As stated before, the land on which the city is built would be owned by representatives of the community. Also, each garden city would provide municipal services or contract them out depending on cost and efficiency factors. Howard sought to create each garden city as separate autonomous communities.

The garden city concept, so far, is as follows: Howard suggested that:

"a group of people (with commercial competence) should create a limited dividend company, borrowing money to establish a garden city in the country side, far enough from the cities to ensure that the land was bought at rock-bottom, depressed-agricultural, land values. They should get agreement from leading industrialist to move their factories there; their workers would move too, and would build their own houses. The garden city would have a fixed limit... [about] 32,000 people living on 1,000 acres of land...It would be surrounded by a much larger area of permanent greenbelt, also owned by the company." (Hall, 2002)

As one garden city reached its proposed population limit, another one would be created within the same vicinity. This would eventually create a web of garden cities, connected by rail systems, to help the population of each travel about. Thus the mobility of the population would serve as the basis for social interaction and cultural exchange found in the city. No longer were rural areas a subverted area of inaction, but instead a complex system of connected communities, in constant interaction through weekday commuting and leisurely weekend transportation. In this manner, the garden city avoids the perils of the city slum through incorporating the benefits of cities (mobility, employment, atmosphere, etc.) and the country (nature, lower population, lower rents, etc.). The hoped for end result of the garden city concept would include an interlocked web of community after community, each presiding over its own affairs yet still in constant contact with one another.

In effect, the garden city idea sets forth community control over local affairs in which a board of members has control over the community's proceedings. The job housing balance is adequately addressed through population limits based on employment offered. Also the population limits would reduce the danger of overcrowding, as was present in the slums. The built community would be adjacent to a main factory in which the residents would work for, allowing for easy and quick access to the work place. The interlocking of multiple garden cities would facilitate cultural and social exchange among various groups of people, providing economic stimulus, entertainment, and atmosphere. And in the time of economic depression in which the idea was proposed the concept was designed to create wealth from the land on which the city was built.

\section{The German Translation}

The garden city concept would later be taken by other nations of the time, looking to solve their own urban problems. One such nation was Germany in which Berlin was facing a formidable slum 
population. This summer I had the opportunity to visit the two separate Berlin garden cities of Seimensstadt and Britz to get a first hand understanding of the German garden city built during this era and how planning concepts, such as the garden city, can be adapted differently to fit certain cultural standards.

Where as Howard saw the garden city as being an anarchistic cooperative community, the German inheritors of the concept saw the garden city as the ideal platform from which to create the ideal worker community. One of the main German garden city proponents, Ernest May, described the garden city as providing "uniform box-shapes of.. roof gardens [that] symbolize the idea of collective living in a uniform style, like the similarly shaped honeycombs of a beehive, symbolizing the uniform living conditions of the inhabitants" (Hall, 2002). Sir Peter

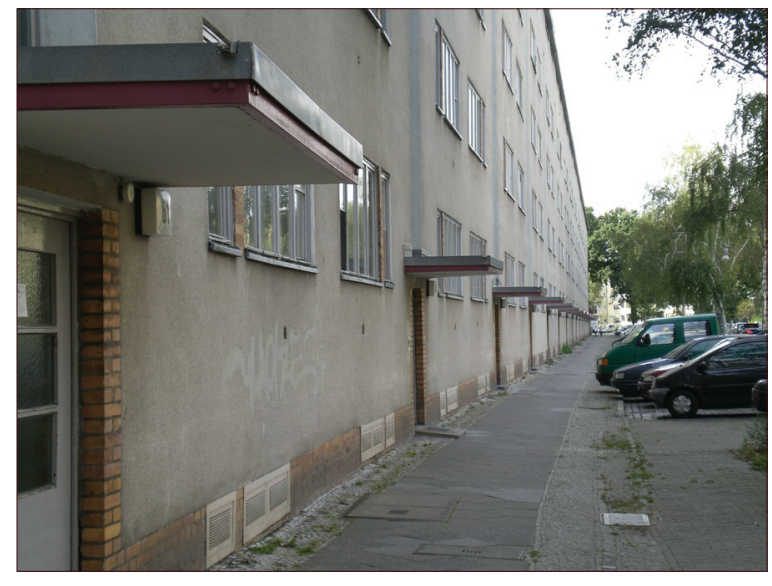

Figure 5

The buildings open up towards the green areas of the site, leaving the street façade as the back of the structures. People who drive through the site but never enter the central courtyards would be left with a bleak and rather uninspiring impression of Siemensstadt.

The first garden city I visited was Siemensstadt, in the northwestern portion of Berlin, only a short subway ride from the center of the city. Siemensstadt was built around a factory of the electric giant Siemens in the 1920's to 1930's. The creation of the project was facilitated by multiple famous German architects of the time, including Scharoun, Bartning, Haering, Gropius and others all putting in modern pieces of architecture (relative to 1920) to reflect the industrial and modern ideal of the creation of the perfect working man's settlement.

From a design perspective the use of many separate and distinctive architects for the entire project creates distinct neighborhoods within the community. The end effect is that of placemaking, a very important design concept to make residents feel more involved with their urban landscape. Thus, through living in Siemensstadt, you could tell people that you live in the flat, pink development on the edge of the settlement, or in the part of the settlement with round curves on

\section{Figure 6}

A playground created to help foster a healthy family life within the settlement. the façade and develop an identity with your living conditions.

The antithesis of this concept in our modern day world would be the endless suburban sprawl where the building types are of the same sort, in endless rows and columns without pause. Through this sprawling and monotonous design, residents feel detached and unimportant in their living environment. In Siemensstadt, the place making within the development makes walking through the site an ongoing exploration, one that actively engages the resident and can foster the building of identity with the development.

The other strong impression gained from visiting Siemensstadt was of the carefully articulated open spaces. The open spaces on site, carefully created and grown to perfection over the years, help fully enclose a user

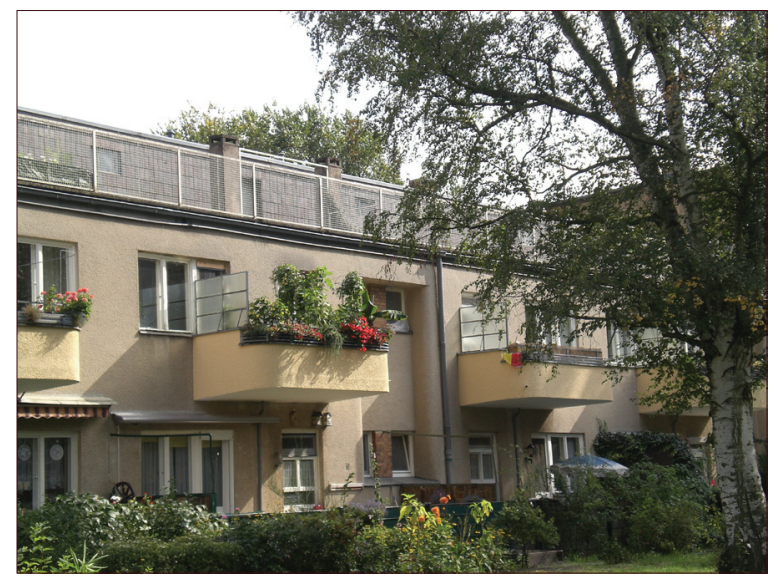




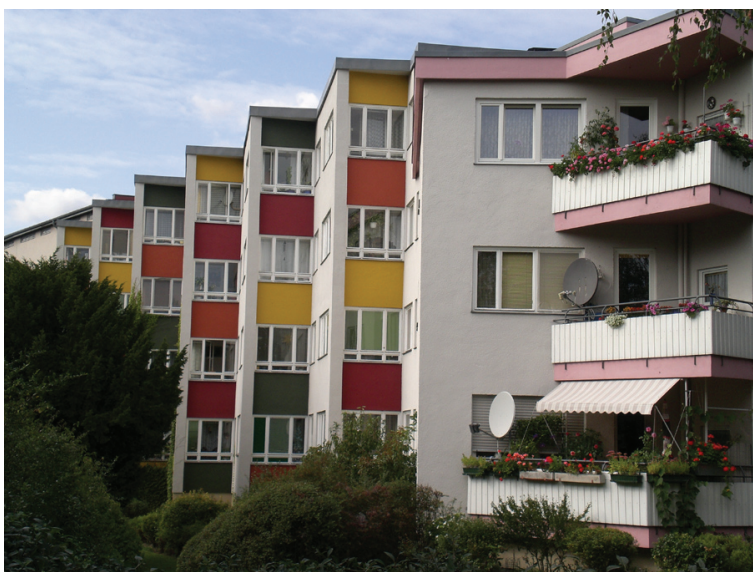

Figure 7

An identity is readily made between a resident and a building through the manipulation of color, architectural form, and varying surrounding vegetation.

Figure 8 The sign post reads "Use ice cover at your own risk". The central open space of Britz is one shared by the inhabitants where the potential for ice skating on the pond in the winter exist.

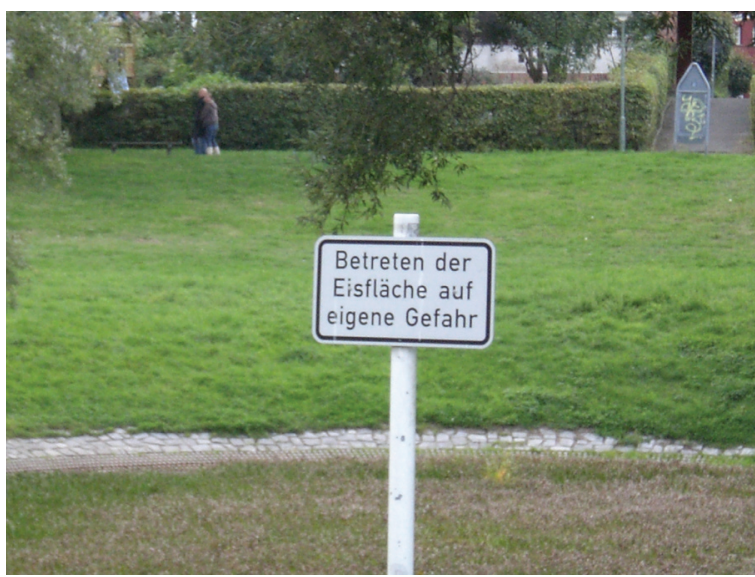

of the site to make the bustle of the city seem like a distance force. All the building units are designed to face these green spaces, not the streets as is typical with most developments today. This shows how it was the architect's intent to make the open spaces the focal point of their design. Balconies for relaxation, main entrances, and such are all present on this side. The overall effect of these open spaces, even though the residential area is geographically right next to the factory, makes all sense of work duties and responsibilities fade away as one enters the expansive lawns and mini forests of the open spaces scattered throughout the development.

I asked my traveling companion to consider how he would feel living in such a development, and he simply replied "There would be no privacy". I agreed with my traveling companion, but in a different manner. For me, instead of focusing on a lack of privacy, I felt as though there was a great opportunity for community to be formed between the residents. Because of the close quarters and shared open spaces, it seemed like human interaction was common and that you would get to know your neighbor and others through living there. This was the last impression I had of Siemensstadt as me and my traveling companion left for the next German garden city, Britz.

The garden settlement of Britz exhibits a new level of design I have never fully experienced before in my career as a planning student. The development is located in the southern part of Berlin and consists of a four story structure wrapped around a central open space in the shape of a horseshoe accompanied by a number of two to three story structures built in a straighter fashion around this horseshoe structure. The horseshoe structure is the defining structure of the development and creates a feeling of total enclosure once entered. The clear definition of space on all sides by the straight façade allows one to lose sense of the out-lying city. Thus, the main part of Britz is a very inward focused area, with the units looking towards one common public space and rejecting the outside world. It is my guess that the intent of this design was to help create an optimum living and family environment for the worker. The worker could leave work and enter a new environment that resembles nothing of where he just came from, despite being relatively close to his place of employment. This environment, unlike his working conditions of factory work, would allow the worker to foster and focus on family affairs, hopefully to generate a happier and healthier lifestyle. Through this, the worker increases his relative productiveness.

The Britz development brings to mind the ideal transcribed by Ernest May, in trying to create homogeneous living conditions for the worker to thrive in. The units are all fashioned in a single manner in the horseshoe structure, which since it is so closed to the rest of the city, perpetuates a uniform living environment for the resident. This is opposed to a more traditional development built along side a roadway, where constant interaction of different forces that utilize the road change the outlook from the residence. However, in Britz, because of the seclusion of the development and its central open space, the forces of interaction seen from a balcony or window are most likely the same scene developing of children playing in the grass and of fellow residents enjoying the 
outdoors. In essence, the only users of the area would be the residents who, because of the homogeneous nature of the development and its units, would be of the same social class as the rest. Because of this, the creation of a separate entity that manifests itself differently than the out-lying city is possible. This of course can be broken when the resident leaves the inside of the complex, but when one lives inside of the complex, the homogeneous nature of the residents surroundings would be dominant. In leaving Britz, I felt this breaking off from the seclusion of the inside and reemerging into the city.

The German garden cities built during the 1920's and 1930's were a direct urban manifestation of the social situation and needs of the time. Today, the ideas behind the garden city concept, such as the interconnection of multiple cities through rail systems, the creation of dense, non-sprawling

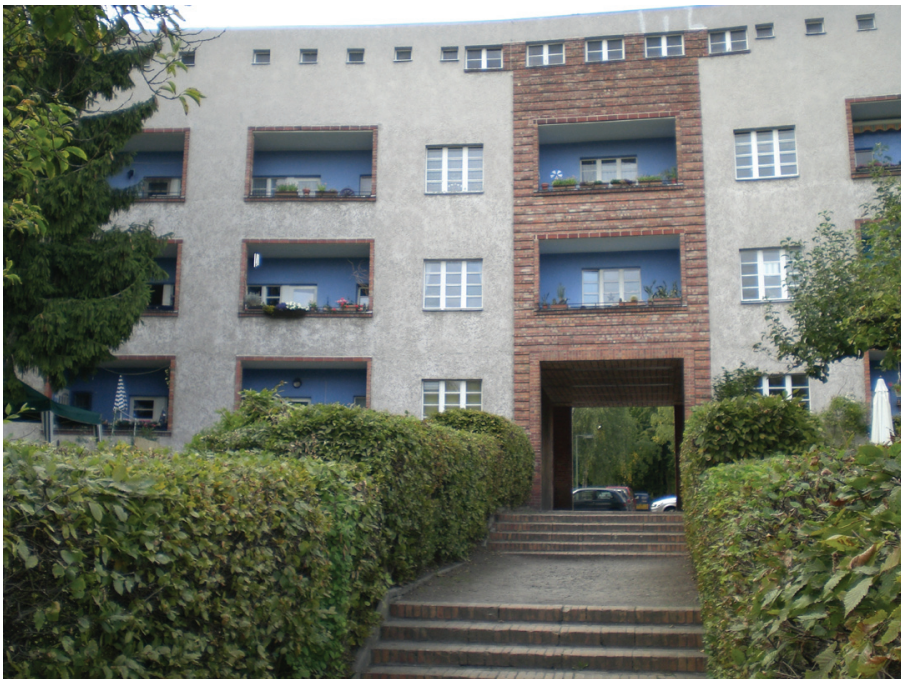

Figure 9

One of the few entry ways to the center of the horseshoe structure as seen from within. be a changing force in how we live out our lives in urban environments: the study and application of city planning.

\section{REFERENCES}

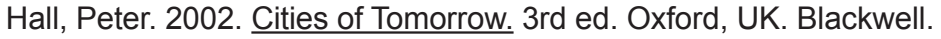

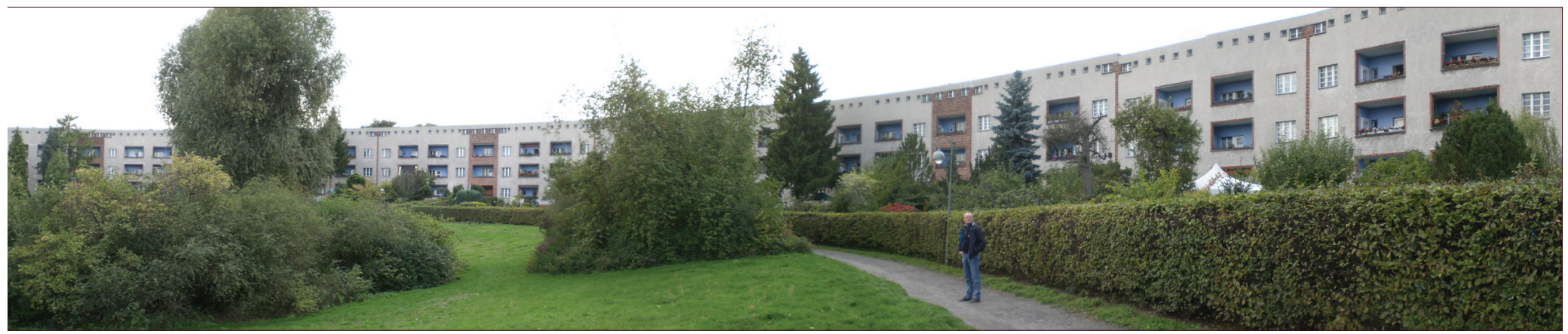

Figure 10

A panoramic view of the horseshoe structure, showing the total enclosure the site creates. 